\title{
Resection of meningiomas in octogenarians: a comparison with a younger geriatric population
}

\author{
Marco V. Corniola, MD,, Jean-Michel Lemée, MD, PhD, ${ }^{1}$ and Torstein R. Meling, MD, DPhil ${ }^{1,2,4}$ \\ ${ }^{1}$ Department of Clinical Neurosciences, Division of Neurosurgery, Geneva University Hospitals, Geneva; ${ }^{2}$ Faculty of Medicine, \\ University of Geneva, Switzerland; ${ }^{3}$ Division of Neurosurgery, Angers University Hospital, Angers, France; and ${ }^{4}$ Department of \\ Neurological Surgery, Istituto Nazionale Neurologico "C. Besta," Milan, Italy
}

\begin{abstract}
OBJECTIVE Intracranial meningiomas (ICMs) may be diagnosed in octogenarians. Since the lesions are rarely lifethreatening, surgery is a questionable choice in this age group. The authors' aim in this study was to analyze factors associated with the extent of resection (EOR), overall survival (OS), and postoperative complications in octogenarians undergoing ICM surgery, by using a cohort of septuagenarians as a reference.
\end{abstract}

METHODS All patients $\geq 70$ years of age who underwent surgery at Oslo University Hospital for an ICM between 1990 and 2010 were included in this study. Data on these cases were retrospectively (1990-2002) and prospectively (2003-2010) acquired from a databank belonging to Oslo University Hospital. All related preoperative imaging studies or reports (earlier cases) were reviewed to confirm tumor location, the presence of bone invasion, and the postoperative EOR.

RESULTS In this study, 49 octogenarians ( 29 females [59.2\%], mean age $83.3 \pm 2.5$ years) were compared with 272 septuagenarians ( 173 females [63.6\%], mean age $74.3 \pm 2.7$ years). Forty octogenarians ( $81.6 \%$ ) and 217 septuagenarians $(79.8 \%)$ underwent gross-total resection. Simpson grade IV resection was achieved in 9 octogenarians (18.4\%) and 4 septuagenarians $(1.4 \%)$, while Simpson grade $V$ resection was obtained in 4 septuagenarians (1.4\%). Postoperative complications were similar in both groups, and 4 octogenarians (8.2\%) and 11 septuagenarians $(4.1 \%)$ died within 30 days after surgery $(p=0.25)$. No octogenarian underwent adjuvant radiotherapy. The OS was $4.2 \pm 2.8$ years in the octogenarians and $5.8 \pm 4.4$ years in the septuagenarians $(p<0.001)$. Female $\operatorname{sex}(\mathrm{OR} 0.36,95 \% \mathrm{Cl} 0.14-0.93 ; p=0.03)$ and a preoperative Karnofsky Performance Scale score $\geq 70$ (OR $0.27,95 \% \mathrm{Cl} 0.10-0.72 ; p=0.009)$ were correlated to the OS.

CONCLUSIONS Octogenarians undergoing surgery for ICMs had an overall reduced OS compared to septuagenarians. However, the clinical relevance of this difference in OS is debatable and has to be put in perspective with expected survival without surgery. Data on symptoms upon admission, EOR, invasive tumor features, and postoperative complications in octogenarians are similar to those observed in septuagenarians. Therefore, the decision concerning whether surgery should be performed must be based on a case-by-case discussion, and surgery should not be immediately dismissed when it comes to ICMs in octogenarians.

https://thejns.org/doi/abs/10.3171/2020.7.FOCUS20306

KEYWORDS meningioma; elderly; overall survival; microsurgery; oncology

$\mathrm{I}$ NTRACRANIAL meningiomas (ICMs) are mostly benign lesions representing approximately $30 \%$ to $40 \%$ of all primary tumors of the central nervous system..$^{1,2}$ Given an aging population and greater availability of MRI, ICMs are increasingly diagnosed. ${ }^{3}$ In patients with growing and/ or symptomatic meningiomas, resection is the preferred treatment option. ${ }^{1}$ As most meningiomas affect patients sometime between their fifth decade and the years following their retirement, it is not uncommon to diagnose ICMs in patients older than 80 years of age. ${ }^{4-6}$ The majority of Western countries define retirement age as beginning during the seventh decade. It is expected that a substantial proportion of patients between 70 and 79 years of age enjoy a more independent status than patients 80 years and

ABBREVIATIONS EOR = extent of resection; GTR = gross-total resection; ICM = intracranial meningioma; KPS = Karnofsky Performance Scale; OS = overall survival; $\mathrm{OUH}=$ Oslo University Hospital; RLE = residual life expectancy; WHO = World Health Organization.

SUBMITTED April 8, 2020. ACCEPTED July 17, 2020.

INCLUDE WHEN CITING DOI: 10.3171/2020.7.FOCUS20306. 
older. In 2018, for example, about $1.5 \%$ of Swiss people 65-79 years of age were living in retirement homes, compared with $15.3 \%$ of octogenarians.?

Among several factors, continual advances in sociomedical care worldwide are allowing patients to live longer and stay in better shape. ${ }^{8}$ As a result, patients may enjoy several years of healthy autonomous as well as independent life after retirement. In parallel, technical and medical innovations in microsurgery and anesthesiology have had a tremendous impact on the surgical management of brain tumors, ${ }^{9-11}$ up to a point at which cranial surgery is considered even in patients of advanced ages. ${ }^{6,10,12-14}$ To do so, a thorough assessment of the benefit-to-risk ratio is of paramount importance, especially when it comes to ICM surgery in the elderly.

Regarding functional impairment, $1.9 \%$ of people $65-$ 79 years of age were unable to carry out daily housework tasks, compared to $6.3 \%$ in octogenarians. ${ }^{7}$ Moreover, $1.8 \%$ of septuagenarians had difficulty taking care of themselves (showers, daily basic care) versus $5.3 \%$ of octogenarians. Last, $7.9 \%$ of people $65-79$ years old reported difficulty with walking even short distances versus $15 \%$ of octogenarians. ${ }^{7}$ Consequently, 80 years of age seems to represent some kind of "functional threshold" observed in the geriatric population.

ICMs are often cured by surgery:11,14-16 they are rarely life-threatening but may have negative effects on function and may impair a patient's quality of life. ${ }^{1}$ This raises an important question regarding the appropriateness of surgery in the very elderly. ${ }^{17}$ Our aim was to analyze specific factors associated with the extent of resection (EOR), overall survival (OS), and postoperative complications in octogenarians ( $\geq 80$ years old) undergoing craniotomies for ICMs, by comparing that group with a cohort of septuagenarians (70-79 years old) used as a reference.

\section{Methods \\ Patient Cohorts}

Data were retrospectively (1990-2002) and prospectively (2003-2010) acquired from a databank belonging to Oslo University Hospital (OUH) that covers approximately 3 million inhabitants, constituting up to $60 \%$ of the Norwegian population.

All patients 70 years or older who underwent surgical resection of an ICM at OUH during the study period were included. All related preoperative imaging studies or reports (earlier cases) were reviewed to confirm the tumor location, the presence of bone invasion, and the postoperative EOR.

The neurosurgical teams of OUH performed surgery in all patients included in the study. The EOR was assessed using the Simpson grading system, ${ }^{18}$ based on data from the surgical report in conjunction with postoperative imaging. Gross-total resection (GTR) was defined as Simpson grade I-III resection in accordance with the latest recommendations. ${ }^{1,10}$ Any cause of death was considered in the analysis of the OS.

The histopathological diagnosis and the World Health Organization (WHO) grading of ICMs were confirmed by a senior, experienced neuropathologist. The 2016 WHO grading system was used to classify the histological characteristics of meningiomas. The WHO criteria changed during the study period. From 1990 to 2001, the tumors were classified as 1) benign, 2) atypical, or 3) anaplastic; later they were reclassified according to the 2016 WHO classification as 1 ) benign $=$ WHO grade $I, 2)$ atypical $=$ WHO grade II, and 3) anaplastic $=$ WHO grade III.

\section{Ethics}

The study was regulated by the Personal Data Act/Personal Health Data Filing System Act and approved by the Data Protection Official at OUH (2017/5204). Informed consent was not required according to the Personal Data Act/Personal Health Data Filing System Act.

\section{Statistical Analysis}

Statistical analysis was performed using $\mathrm{R}$ version 3.5.1 (https://www.r-project.org). Significance was set at $\mathrm{p}=0.05$. A multivariate analysis was performed using a linear generalized model approach. To do so, the variables considered were patient's age, sex, preoperative Karnofsky Performance Scale (KPS) score, and clinical status as well as tumor location, WHO histopathological grade, and the presence of bone invasion. Also, the presence of a postoperative complication and the use of adjuvant radiation therapy were considered. Mean values are reported with standard deviations $( \pm \mathrm{SD})$.

\section{Results}

\section{Baseline Demographics and Symptoms on Admission}

Baseline demographics and symptoms on admission are summarized in Table 1. The demographic, radiological, surgical, and postoperative data obtained in the 49 patients allocated to the $\geq 80$ years of age cohort ( $29 \mathrm{fe}$ males [59.2\%], mean age $83.3 \pm 2.5$ years) were compared to those in a reference cohort of 272 patients $70-79$ years of age (173 females [63.6\%], mean age $74.3 \pm 2.7$ years).

Regarding preoperative KPS scores and presenting symptoms on admission, the two subgroups were similar, despite the fact that the $\geq 80$ years of age group displayed a tendency toward a reduced preoperative KPS score when compared to patients 70-79 years of age. However, this difference did not reach statistical significance $(73.4 \pm$ 44.6 vs $86 \pm 34.7$, respectively; $p=0.06$ ). In the $\geq 80$ years of age cohort, 4 patients $(8.2 \%)$ were asymptomatic on admission, 13 (26.5\%) presented with seizures, 19 (38.8\%) had intracranial hypertension, and $33(67.3 \%)$ presented with a focal neurological deficit; similar numbers and proportions were found in the reference cohort (Table 1).

\section{Tumor Characteristics}

Baseline tumor characteristics are summarized in Table 1 . In the $\geq 80$ years of age cohort, the majority of patients (44 patients, $89.8 \%$ ) harbored WHO grade I meningiomas, while 4 patients (8.2\%) had WHO grade II and 1 patient $(2.0 \%)$ had WHO grade III tumors. The following distribution of WHO grades was observed in the 70-79 years of age cohort: 248 patients $(91.2 \%)$ with WHO grade I, $17(6.2 \%)$ with WHO grade II, and seven (2.6\%) with 
TABLE 1. Baseline demographics and clinical, radiological, surgical, and outcome data in geriatric patients stratified by age group

\begin{tabular}{|c|c|c|c|c|c|}
\hline & \multicolumn{2}{|c|}{ Patients $\geq 80$ Yrs of Age } & \multicolumn{2}{|c|}{ Patients $70-79$ Yrs of Age } & \multirow[b]{2}{*}{ p Value } \\
\hline & $n=49$ & $\%$ & $n=272$ & $\%$ & \\
\hline \multicolumn{6}{|c|}{ Baseline demographics \& symptoms on admission } \\
\hline Age in yrs, mean $\pm \mathrm{SD}$ & $83.3 \pm 2.5$ & & $74.3 \pm 2.7$ & & \\
\hline Sex & & & & & 0.63 \\
\hline $\mathrm{F}$ & 29 & 59.2 & 173 & 63.6 & \\
\hline M & 20 & 40.8 & 99 & 36.4 & \\
\hline Preop KPS score, mean \pm SD & $73.4 \pm 44.6$ & & $86 \pm 34.7$ & & 0.06 \\
\hline \multicolumn{6}{|l|}{ Presenting symptom } \\
\hline Asymptomatic & 4 & 8.2 & 13 & 4.8 & 0.28 \\
\hline Seizures & 13 & 26.5 & 85 & 31.2 & 0.61 \\
\hline $\mathrm{ICH}$ & 19 & 38.8 & 86 & 31.6 & 0.33 \\
\hline Focal neurological deficit & 33 & 67.3 & 161 & 59.2 & 0.34 \\
\hline \multicolumn{6}{|l|}{ Tumor characteristics } \\
\hline WHO grade & & & & & 0.82 \\
\hline 1 & 44 & 89.8 & 248 & 91.2 & \\
\hline II & 4 & 8.2 & 17 & 6.2 & \\
\hline III & 1 & 2.0 & 7 & 2.6 & \\
\hline Skull base tumor & 13 & 26.5 & 112 & 41.2 & 0.06 \\
\hline Bone invasion & 6 & 12.2 & 46 & 16.9 & 0.53 \\
\hline \multicolumn{6}{|l|}{ Surgical outcome } \\
\hline Simpson grade & & & & & 0.87 \\
\hline 1 & 20 & 40.8 & 104 & 38.2 & \\
\hline II & 16 & 32.7 & 100 & 36.8 & \\
\hline III & 4 & 8.2 & 13 & 4.8 & \\
\hline IV & 9 & 18.4 & 51 & 18.8 & \\
\hline V & 0 & 0 & 4 & 1.5 & \\
\hline GTR & 40 & 81.6 & 217 & 79.8 & 0.80 \\
\hline \multicolumn{6}{|l|}{ Postop complications } \\
\hline Hematoma & 3 & 6.1 & 14 & 5.1 & 0.73 \\
\hline Infection & 0 & 0.0 & 9 & 3.3 & 0.36 \\
\hline Neurological worsening & 6 & 12.2 & 29 & 10.7 & 0.42 \\
\hline 30-day mortality & 4 & 8.2 & 11 & 4.0 & 0.25 \\
\hline Adjuvant radiotherapy & 0 & 0 & 3 & 1.1 & 1 \\
\hline $\mathrm{OS}$ in yrs, mean $\pm \mathrm{SD}$ & $4.2 \pm 2.8$ & & $5.8 \pm 4.4$ & & $<0.001$ \\
\hline
\end{tabular}

GTR = gross-total resection as defined by the European Association for Neuro-Oncology (Simpson grades I-III); ICH = intracranial hypertension.

Boldface type indicates statistical significance.

WHO grade III. Skull base location was found in 13 patients $(26.5 \%) \geq 80$ years of age and 112 patients $(42.3 \%)$ $70-79$ years of age $(p=0.06)$. The incidence of bone invasion was found to be similar between both cohorts (6 patients [12.2\%] in the $\geq 80$ years of age group vs 46 patients [16.9\%] in the 70-79 years of age group).

\section{Surgical Management}

Data on surgical management of ICMs in both cohorts are shown in Table 1. GTR was achieved in 40 patients $(81.6 \%)$ in the $\geq 80$ years of age cohort and in 217 patients (79.8\%) in the 70-79 years of age cohort. More specifical- ly, a Simpson grade I resection was achieved in 20 patients $(40.8 \%)$ in the $\geq 80$ years of age group and in 104 patients (38.2\%) in the 70-79 years of age cohort, whereas Simpson grade IV was achieved in 9 patients $(18.4 \%)$ in the $\geq$ 80 years of age cohort and in 51 patients $(18.8 \%)$ in the 70-79 years of age cohort. No biopsies were performed in the $\geq 80$ years of age cohort, while Simpson grade V resection was achieved in 4 patients $(1.4 \%)$ in the $70-79$ years of age cohort.

The occurrence of postoperative complications (hematoma, infection, and/or neurological worsening) was equally distributed between both groups. Four patients (8.2\%) 
TABLE 2. Predictive factors of overall survival in patients $\geq 80$ years of age

\begin{tabular}{lcc}
\hline & \multicolumn{2}{c}{ Overall Survival } \\
\cline { 2 - 3 } & OR $(95 \% \mathrm{Cl})$ & $\mathrm{p}$ Value \\
\hline Female sex & $0.36(0.14-0.93)$ & $\mathbf{0 . 0 3}$ \\
\hline Preop KPS score $\geq 70$ & $0.27(0.10-0.72)$ & $\mathbf{0 . 0 0 9}$ \\
\hline WHO grade & $1.45(0.32-6.55)$ & 0.63 \\
\hline Skull base location & $1.47(0.25-2.24)$ & 0.61 \\
\hline Simpson grade & $1.05(0.67-1.66)$ & 0.83 \\
\hline Postop hematoma & $1.73(0.18-16.69)$ & 0.63 \\
\hline Postop radiation therapy & $1.14(0.22-5.89)$ & 0.87 \\
\hline
\end{tabular}

Boldface type indicates statistical significance.

in the $\geq 80$ years of age cohort and 11 patients $(4.0 \%)$ in the 70-79 years of age cohort died within 30 days after surgery $(p=0.25)$. In the $\geq 80$ years of age group, no patient underwent adjuvant radiotherapy, whereas 3 patients $(1.1 \%)$ in the $70-79$ year of age cohort did so.

\section{Overall Survival}

The OS was $4.2 \pm 2.8$ years and $5.8 \pm 4.4$ years in the $\geq$ 80 and $70-79$ years of age cohorts, respectively $(p<0.001)$ (Table 1).

\section{Predictive Factors of Overall Survival}

The predictive factors considered in the analysis are shown in Table 2. Among sex, preoperative KPS score $\geq$ 70 , WHO grade of tumor and Simpson grade of resection, skull base location of tumor, the occurrence of postoperative hematoma, and the use of postoperative radiation therapy, only female sex (OR 0.36, 95\% CI 0.14-0.93; p = 0.03 ) and preoperative KPS score $\geq 70$ (OR $0.27,95 \%$ CI $0.10-0.72 ; \mathrm{p}=0.009$ ) were correlated to the OS.

\section{Discussion}

In this single-center study, we provide data on geriatric patients divided into 49 octogenarians and 272 septuagenarians, showing that octogenarian patients did not display a higher incidence of complications or 30-day mortality after surgery for ICMs. The OS was the only statistically different variable between the two cohorts. To our knowledge, this is the first publication to assess such pre- and postoperative factors in octogenarians compared to septuagenarians.

Both groups shared similar characteristics in sex distribution, symptoms upon admission, bone invasion, EOR, postoperative complications, and adjuvant therapy. As previously reported, skull base ICMs were underrepresented in octogenarians $(26.5 \%$ vs $42.3 \%$ in the $70-79$ years of age cohort; $p=0.06$ ), indicating that skull base ICMs are generally treated by surgery at younger ages, ${ }^{16,19-24}$ reflecting a selection bias.

As the incidence of postoperative complications and 30-day mortality were similar between the two groups, the slightly shorter OS for octogenarians (mean 1.6 years) is probably related to the age of the patients rather than to the surgery or the pathology itself, since the OS was calculated regardless of the cause of death. This is of paramount importance, as it indicates that biology is the most determinant variable for survival and not the intervention per se. In this perspective, we support a surgical attitude toward meningiomas, even in octogenarians, as long as patients are carefully selected on the basis of their preoperative functional status and general condition.

The baseline KPS score on admission was slightly lower in the octogenarians than in the septuagenarians (mean KPS scores $73.4 \pm 44.6$ vs $86 \pm 34.7 ; p=0.06$ ). The reason for this probably lies in stricter patient selection prior to surgery in the octogenarian group. There is potential for a dramatic effect of surgical intervention on functional status. Hence, only those octogenarians who experienced tumor-related impairment of functional status and who were otherwise in good shape to withstand surgery, as well as subsequent hospitalization, were treated surgically. Conversely, older patients who presented with preserved functional status and an incidental, asymptomatic ICM were probably not deemed good candidates for surgery. This assumption is also supported by previously reported data showing that elderly patients with surgically managed ICMs have a higher in-hospital mortality rate, higher rate of discharge to a facility other than home, and longer length of hospital stay. ${ }^{25}$ However, one must keep in mind that stereotactic radiosurgery is a viable option for octogenarians and septuagenarians presenting with smaller meningiomas and medical contraindications to surgery. ${ }^{26}$

The balance of risks should be carefully assessed, and only those patients with impaired functional status are likely to benefit from surgery. Furthermore, the KPS score can be influenced by chronic medical conditions or past surgical interventions, potentially impairing the patient's functional status; this is particularly true for the $\geq 80$ years of age group, making it difficult to discern the impact of the ICM itself on the patient's KPS score. Unfortunately, we were not able to retrieve data on comorbidities in our cohort, which limits the analysis and elaboration of the frailty score.

\section{Appropriateness of Surgical Management of ICMs in Octogenarians}

Nowadays, neurosurgeons face an increasingly aging population on a daily basis. The surgical decision-making for octogenarians is challenging with respect to the benefit-to-risk assessment. This is particularly true for benign ICMs, which can be fully controlled by maximal surgical resection and appropriate follow-up. Unlike glioblastoma multiforme, ICMs do not dramatically reduce the life expectancy of patients, as long as appropriate management is applied. ${ }^{1,5,27}$ From the perspective of surgical risk assessment, our data show that octogenarians do not have higher incidences of postoperative hematomas, infection, or neurological worsening than septuagenarians. In addition, the 30-day mortality rate is comparable between groups. These data are in line with findings presented in previously published literature; ${ }^{4,6,12,28}$ therefore, ICM surgery should be considered for octogenarians as long as the tumor is accessible to surgery and the patient presents with some potential of recovery. 


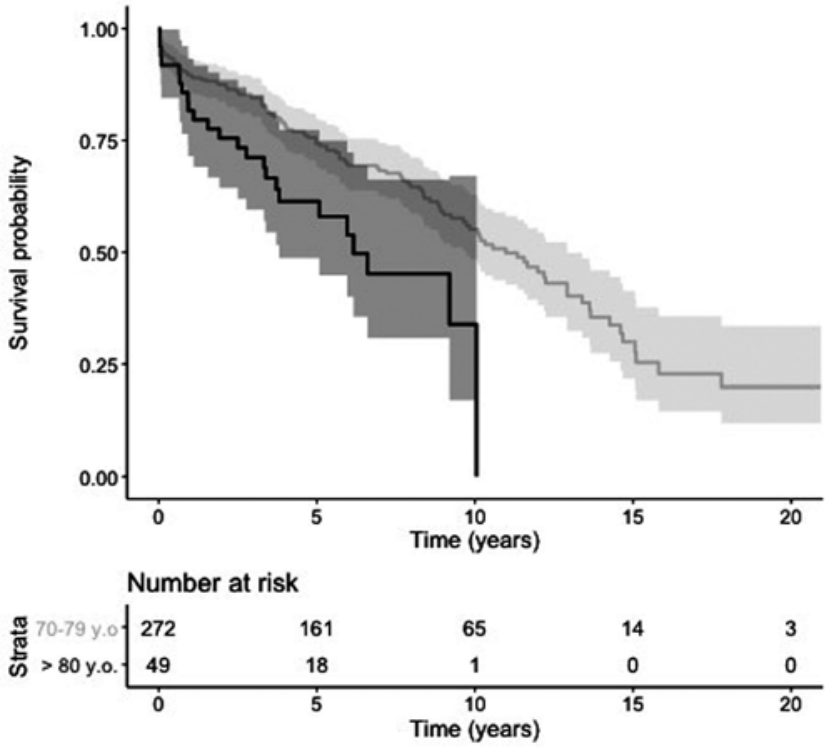

FIG. 1. Overall survival of patients $\geq 80$ years old (dark gray) and of those between 70 and 79 years old (light gray). y.o. = years old.

\section{Is It Worth It?}

Residual life expectancy (RLE) should also be thoroughly considered when confronted with an octogenarian with a symptomatic ICM. The central questions are: 1) is the ICM likely to shorten the patient's life, and 2) can resection prevent this with an acceptable risk?

In 2010 (i.e., the final year of our study), the overall RLE in Norway for an 83-year-old (mean age of our octogenarian cohort) in the general population was 7.2 years (6.3 and 7.7 years for men and women, respectively). ${ }^{29}$

Our data on OS are certainly limited; yet we are able to show a limited benefit regarding RLE following meningioma surgery in the $\geq 80$ years of age group. As shown in Table 1 and Fig. 1, the OS of the octogenarians was a mean of 1.6 years shorter than that of the septuagenarians $(4.2 \pm 2.8$ years vs $5.8 \pm 4.4$ years; $p<0.001)$. Despite the fact that the difference is statistically significant, its clinical relevance is debatable, since it has to be put in the perspective of expected survival in elderly patients without surgery. Unfortunately, we cannot provide a conclusion on this point, since only cases managed surgically were involved in this study.

Nevertheless, it is not possible to discriminate between excessive mortality due to the ICMs and age-related natural history, since we do not provide data on disease-specific mortality. The decision to operate or not must be based on a case-by-case discussion, relying on the surgeon's clinical judgment, the patient's potential for recovery, and the patient's involvement in the discussion.

Case selection in elderly patients may be difficult, especially in borderline situations (e.g., a patient with KPS score 60 and a right frontal convexity meningioma). Refining patient selection is therefore important. Konglund et al. ${ }^{6}$ reported on the usefulness of the SKALE score (based on sex, KPS score, American Society of Anesthesiologists class, location of tumor, and peritumoral edema grading system) to reflect the mortality rate at 1 month and 1 year after surgery in 80- to 90 -year-old patients presenting with symptomatic ICMs. Together with a thorough preoperative assessment, the SKALE score seems a useful and straightforward tool to select elderly patients for surgery. ${ }^{6}$ Other groups have assessed scores such as the Clinical-Radiological Grading System and the Geriatric Scoring System as well as prognostic factors for outcomes in the elderly. ${ }^{30-34}$ Notably, it was shown by Konglund and colleagues ${ }^{12}$ that elderly patients, between 60 and 84 years of age, who underwent surgery for ICMs significantly improved in cognitive function after surgery. This is of paramount importance because a significant proportion of patients with ICMs present with impaired cognitive function upon admission. ${ }^{35}$

Finally, our results show that the incidence of postoperative complications requiring repeated surgery in the $\geq 80$ years of age cohort was similar to that observed in the 7079 years of age cohort. In a recent study from Steinberger et al. ${ }^{36}$ age older than 80 years was an independent predictor for postoperative complications, increased 30-day mortality rate, and extended hospital length of stay. Similarly, Lassen et al. ${ }^{37}$ reported a surgical mortality rate at 30 days of $2.3 \%$ and found that age $\geq 60$ years was a risk factor in a cohort of 2630 patients who underwent craniotomies for intracranial tumors. In line with previously reported data from Steinberger et al., ${ }^{36}$ our results on 30-day mortality rates show an increase to $4.0 \%$ in septuagenarians, which was even higher (8.2\%) in octogenarians. Together, these data illustrate the relationship between age and surgical mortality in patients with ICM.

\section{Strengths and Limitations}

Our dataset offers a comprehensive and very extended source of information on patients with ICMs with complete follow-up, since only one patient was lost during the study period, due to moving abroad. The clinical setting, the number of patients, and the length of follow-up (up to 21 years) are also strengths of our clinical study. All patients with a postoperative complication or disease recurrence were systematically referred again to our tertiary center. The data stem from one neurosurgical center with mostly homogeneous surgical practices. All patients in the specified age groups who harbored a histologically confirmed meningioma were included, which reduces selection bias.

The partial retrospective nature of data collection prior to 2003 is certainly a limitation. Grading of tumors was done according to two different WHO classifications, as mentioned in the Methods. Tumor size and molecular biomarkers of proliferation such as MIB-1 were not available due to the long period of data collection, which began in 1990. Despite being known factors influencing OS, ${ }^{38}$ data on these factors are not available. Surgical and monitoring techniques evolved during the study period and probably also reflect on the OS. The difference in the proportions of Simpson grade IV surgeries in the octogenarians and septuagenarians ( $18.4 \%$ and $18.8 \%$, respectively) possibly induced a bias in the survival results. Only patients undergoing surgery were included in the study; therefore, no data on observation, radiosurgery, or fractionated radiation therapy could be retrieved. 
In terms of mortality, no disease-specific survival was registered. Therefore, no conclusion on ICM-related excessive mortality rate can be drawn on the basis of our data. Finally, the reported survival data are applicable to Norway. Although corroborated by US data from the Centers for Disease Control and Prevention, Norwegian data are probably not translatable to the rest of the world and, therefore, the RLE should be analyzed in other countries.

\section{Conclusions}

Our results suggest that the benefit of ICM surgery in octogenarians is limited with respect to OS, because we observed a reduced OS in this age cohort compared to data obtained in the 70-79 years of age cohort and compared to data available from the general population. However, data on symptoms upon admission, the EOR, invasive tumor features, and postoperative complications are similar to those observed in younger geriatric patients. As the disease-specific mortality rate of octogenarians who have been surgically treated for ICMs is still undetermined, the decision to operate or not must be based on a case-by-case discussion involving clinical judgment and patient adherence to the treatment. Therefore, surgery should not be immediately dismissed when confronted with a patient $\geq 80$ years of age who harbors an ICM.

\section{References}

1. Goldbrunner R, Minniti G, Preusser M, et al. EANO guidelines for the diagnosis and treatment of meningiomas. Lancet Oncol. 2016;17(9):e383-e391.

2. Lorez M, Nanieva R, Arndt V, Rohrmann S. Benign and malignant primary brain tumours in the Swiss population (2010-2014). Schweizer Krebsbulletin. 2018;38(2):188-196.

3. Solheim O, Torsteinsen M, Johannesen TB, Jakola AS. Effects of cerebral magnetic resonance imaging in outpatients on observed incidence of intracranial tumors and patient survival: a national observational study. J Neurosurg. 2014; 120(4):827-832.

4. Meling TR, Da Broi M, Scheie D, Helseth E. Skull base versus non-skull base meningioma surgery in the elderly. Neurosurg Rev. 2019;42(4):961-972.

5. Lemée JM, Joswig H, Da Broi M, et al. WHO grade I meningiomas: classification-tree for prognostic factors of survival. Neurosurg Rev. 2020;43(2):749-758.

6. Konglund A, Rogne SG, Helseth E, Meling TR. Meningioma surgery in the very old-validating prognostic scoring systems. Acta Neurochir (Wien). 2013;155(12):2263-2271.

7. Swiss Federal Office of Statistics. Santé des personnes âgées. Accessed August 20, 2020. https://www.bfs.admin.ch/bfs/fr/ home/statistiques/sante/etat-sante/personnes-agees.html

8. Kontis V, Bennett JE, Mathers CD, et al. Future life expectancy in 35 industrialised countries: projections with a Bayesian model ensemble. Lancet. 2017;389(10076):1323-1335.

9. Patra DP, Savardekar AR, Dossani RH, et al. Meningioma: the tumor that taught us neurosurgery. World Neurosurg. 2018;118:342-347.

10. Corniola MV, Lemée JM, Schaller K, Meling TR. Lateral sphenoid wing meningiomas without bone invasion-Still skull base surgery? Neurosurg Rev. Published online October 29, 2019. doi:10.1007/s10143-019-01181-6

11. Meling TR, Da Broi M, Scheie D, et al. Meningioma surgery-Are we making progress? World Neurosurg. 2019;125: e205-e213.

12. Konglund A, Rogne SG, Lund-Johansen M, et al. Outcome following surgery for intracranial meningiomas in the aging. Acta Neurol Scand. 2013;127(3):161-169.

13. Corniola MV, Lemée JM, Da Broi M, et al. Posterior fossa meningiomas: perioperative predictors of extent of resection, overall survival and progression-free survival. Acta Neurochir (Wien). 2019;161(5):1003-1011.

14. Corniola MV, Lobrinus JA, Lemée JM, Meling TR. Intracranial meningiomas-Management of the patients in the microsurgery era. Article in French. Rev Med Suisse. 2020; 16(680):283-288.

15. Lemée JM, Corniola MV, Da Broi M, et al. Extent of resection in meningioma: predictive factors and clinical implications. Sci Rep. 2019;9(1):5944.

16. Hasseleid BF, Meling TR, Rønning P, et al. Surgery for convexity meningioma: Simpson Grade I resection as the goal: clinical article. J Neurosurg. 2012;117(6):999-1006.

17. Awad IA, Kalfas I, Hahn JF, Little JR. Intracranial meningiomas in the aged: surgical outcome in the era of computed tomography. Neurosurgery. 1989;24(4):557-560.

18. Simpson D. The recurrence of intracranial meningiomas after surgical treatment. J Neurol Neurosurg Psychiatry. 1957; 20(1):22-39.

19. Arienta C, Caroli M, Crotti F, Villani R. Treatment of intracranial meningiomas in patients over 70 years old. Acta Neurochir(Wien). 1990;107(1-2):47-55.

20. Papo I. Intracranial meningiomas in the elderly in the CT scan era. Acta Neurochir(Wien). 1983;67(3-4):195-204.

21. Umansky F, Ashkenazi E, Gertel M, Shalit MN. Surgical outcome in an elderly population with intracranial meningioma. J Neurol Neurosurg Psychiatry. 1992;55(6):481-485.

22. Cohen-Inbar O, Lee CC, Schlesinger D, et al. Long-term results of stereotactic radiosurgery for skull base meningiomas. Neurosurgery. 2016;79(1):58-68.

23. Morokoff AP, Zauberman J, Black PM. Surgery for convexity meningiomas. Neurosurgery. 2008;63(3):427-434.

24. Scheitzach J, Schebesch KM, Brawanski A, Proescholdt MA. Skull base meningiomas: neurological outcome after microsurgical resection. J Neurooncol. 2014;116(2):381-386.

25. Bateman BT, Pile-Spellman J, Gutin PH, Berman MF. Meningioma resection in the elderly: nationwide inpatient sample, 1998-2002. Neurosurgery. 2005;57(5):866-872.

26. Kondziolka D, Mathieu D, Lunsford LD, et al. Radiosurgery as definitive management of intracranial meningiomas. Neurosurgery. 2008;62(1):53-60.

27. Lemée JM, Corniola MV, Meling TR. Benefits of re-do surgery for recurrent intracranial meningiomas. Sci Rep. 2020; 10(1):303.

28. Black P, Kathiresan S, Chung W. Meningioma surgery in the elderly: a case-control study assessing morbidity and mortality. Acta Neurochir (Wien). 1998;140(10):1013-1017.

29. National Statistical Institute of Norway. Expectation of lifetime, by sex and age 1986-2019. Accessed March 20, 2020. https://www.ssb.no/en/statbank/table/05375/

30. Caroli M, Locatelli M, Prada F, et al. Surgery for intracranial meningiomas in the elderly: a clinical-radiological grading system as a predictor of outcome. J Neurosurg. 2005;102(2): 290-294.

31. Cohen-Inbar O, Soustiel JF, Zaaroor M. Meningiomas in the elderly, the surgical benefit and a new scoring system. Acta Neurochir (Wien). 2010;152(1):87-97.

32. Cohen-Inbar O, Sviri GE, Soustiel JF, Zaaroor M. The Geriatric Scoring System (GSS) in meningioma patients - validation. Acta Neurochir (Wien). 2011;153(7):1501-1508.

33. Chen ZY, Zheng $\mathrm{CH}$, Tang Li, et al. Intracranial meningioma surgery in the elderly (over 65 years): prognostic factors and outcome. Acta Neurochir (Wien). 2015;157(9):1549-1557.

34. Chen WC, Magill ST, Englot DJ, et al. Factors associated with pre- and postoperative seizures in 1033 patients undergoing supratentorial meningioma resection. Neurosurgery. 2017;81(2):297-306. 
35. van Nieuwenhuizen D, Douw L, Klein M, et al. Cognitive functioning and functional brain networks in postoperative WHO grade I meningioma patients. J Neurooncol. 2018; 140(3):605-613.

36. Steinberger J, Bronheim RS, Vempati P, et al. Morbidity and mortality of meningioma resection increases in octogenarians. World Neurosurg. 2018;109:e16-e23.

37. Lassen B, Helseth E, Rønning P, et al. Surgical mortality at 30 days and complications leading to recraniotomy in 2630 consecutive craniotomies for intracranial tumors. Neurosurgery. 2011;68(5):1259-1269.

38. Barrett OC, Hackney JR, McDonald AM, et al. Pathologic predictors of local recurrence in atypical meningiomas following gross total resection. Int J Radiat Oncol Biol Phys. 2019;103(2):453-459.

\section{Disclosures}

The authors report no conflict of interest concerning the materials or methods used in this study or the findings specified in this paper.

\section{Author Contributions}

Conception and design: Corniola, Meling. Acquisition of data: Meling. Analysis and interpretation of data: Corniola, Meling. Drafting the article: Corniola, Meling. Critically revising the article: all authors. Reviewed submitted version of manuscript: Corniola, Meling. Approved the final version of the manuscript on behalf of all authors: Corniola. Statistical analysis: Lemée. Study supervision: Meling.

\section{Correspondence}

Marco V. Corniola: Hôpitaux Universitaires de Genève, Geneva, Switzerland.marco.corniola@hcuge.ch. 